\title{
A novel pathway controlling cambium initiation and - activity via cytokinin biosynthesis in Arabidopsis
}

\author{
Arezoo Rahimi $^{1}$,Omid Karami ${ }^{1, *}$, Angga Dwituti Lestari ${ }^{1}$, Dongbo Shi ${ }^{2}$, Thomas Greb $^{2}$, \\ and Remko Offringa ${ }^{1, *}$ \\ ${ }^{1}$ Plant Developmental Genetics, Institute of Biology Leiden, Leiden University, Sylviusweg 72, 2333 BE \\ Leiden, The Netherlands \\ 2 Department of Developmental Physiology, Centre for Organismal Studies (COS), Heidelberg University, \\ 69120 Heidelberg, Germany
}

* Authors for correspondence (o.karami@biology.leidenuniv.nl;r.offringa@biology.leidenuniv.nl) 


\begin{abstract}
Plant secondary growth, also referred to as wood formation, includes the production of secondary xylem, which is derived from meristematic cambium cells embedded in vascular tissues. Despite the importance of secondary xylem in plant growth and wood formation, the molecular mechanism of secondary growth is not yet well understood. Here we identified an important role for the Arabidopsis thaliana (Arabidopsis) AT-HOOK MOTIF CONTAINING NUCLEAR LOCALIZED 15 (AHL15) gene, encoding for a putative transcriptional regulator, in controlling vascular cambium activity and secondary xylem formation. Secondary xylem development was significantly reduced in inflorescence stems of the Arabidopsis ahl15 lossof-function mutant, whereas AHL15 overexpression led to extensive secondary xylem formation. AHL15 expression under a vascular meristem-specific promoter also enhanced the amount of interfascicular secondary xylem. Moreover, AHL15 appeared to be required for the enhanced secondary xylem formation in the Arabidopsis double loss-of-function mutant of the SUPPRESSOR OF OVEREXPRESSION OF CO 1 (SOC1) and FRUITFULL (FUL) genes. A well-known central regulator of cambial activity is the plant hormone cytokinin. We showed that the expression of two cytokinin biosynthesis genes (ISOPENTENYL TRANSERASE (IPT) 3 and 7) is decreased in ahl15 loss-of-function mutant stems, whereas the secondary xylem deficiency in these mutant stems can be resorted by cambium-specific expression of the Agrobacterium tumefaciens IPT gene, indicating that AHL15 acts through the cytokinin pathway. These findings support a model whereby AHL15 acts as a central factor inducing vascular cambium activity downstream of SOC1 and $F U L$ and upstream of IPT3 , IPT7 and LOG4, LOG5 governing the rate of secondary xylem formation in Arabidopsis inflorescence stems.
\end{abstract}

Keywords: Secondary growth, AHL15, SOC1, FUL, cytokinin, Arabidopsis 


\section{Introduction}

Throughout their lifespan, plants can dynamically change their growth and development in response to environmental signals, and this allows them to adapt and survive adverse conditions. In many flowering plants, but especially in woody plant species, stems show two distinct developmental growth processes. The increase in stem length and the establishment of the primary vascular meristem that is arranged into vascular bundles in young stems are known as primary growth. Each bundle contains a primary vascular meristem, or a procambium, that generates primary xylem towards the center and primary phloem towards the periphery of the stem (Fischer et al., 2019). Later in development, when primary stem growth is completed, the procambium and its neighbouring interfascicular parenchyma cells (between the vascular bundles) differentiate into the cambial meristem, eventually forming a continuous cylinder of stem cells in the primary plant stem. This then initiates the process of secondary growth, during which the cambial meristem continuously generates secondary xylem usually towards the inside of the stem, and secondary phloem towards the outside of the stem, resulting in radial stem expansion (Jouannet et al., 2015).

The vascular cambium is an important meristem, as it produces vascular tissues that transport water and nutrients throughout the plant body. Through secondary growth, it provides mechanical support for the plant body by generating lignified wood cells. The rate of cell division in stem cells of the vascular cambium determines the amount of secondary growth and, thus, whether and how much wood is formed. In view of the use of wood as building material and renewable energy source, there is an obvious demand for an understanding of the genetic mechanisms that control the cambium activity. The model plant Arabidopsis thaliana (Arabidopsis) is herbaceous, but it can undergo secondary growth in the hypocotyl, root, or stem depending on the growth conditions (Ragni and Greb, 2018; Fischer et al., 2019). Most of our current understanding of secondary growth comes from studies in Arabidopsis. Although great progress has been made over the past few years (insert references), the exact signals that initiate the formation of the cambium ring and regulate the amount of secondary growth, and thus differentiate between woody and non-woody species, are still unknown.

Previous studies have revealed a number of molecular factors and genetic components, including phytohormones and transcription factors, that are involved in the establishment and proliferation of cambium cells (Oh et al., 2003; Fischer et al., 2019). The TDIF-PXY-WOX signaling pathway is the best-studied signaling pathway that controls cambium activity. The peptide ligand CLE41/44/TRACHEARY ELEMENT DIFFERENTIATION INHIBITORY FACTOR (TDIF) is synthesized in the phloem and seems to diffuse through the apoplastic space to cambium cells, where it binds to its cognate receptor PHLOEM INTERCALATED WITH XYLEM (PXY). PXY subsequently promotes the proliferation of cambium cells by activating the expression of the cambium-specific WUSCHEL-RELATED HOMEOBOX genes WOX4 and WOX14 (Etchells and Turner, 2010; Hirakawa et al., 2010; Wang et al., 2019). The WOX4 transcription factor promote stem cell proliferation by interacting with the GRAS domain transcription factor HAIRY MERISTEM 4 (HAM4) (Zhou et al., 2015).

Cambium activity is also known to be regulated via a hormonal signaling network (Bhalerao et al., 2016; Immanen et al., 2016; Brackmann et al., 2018; Fischer et al., 2019). Cytokinin is 
a major plant hormone that is well-known to promote cell division in various meristems. In parallel to the TDIF-PXY-WOX pathway, cytokinin signaling has been highlighted as a major positive regulator of vascular cambium cell proliferation during secondary growth (ElShowk et al., 2013). ISOPENTENYL TRANSFERASE (IPT) enzymes are mostly responsible for cytokinin biosynthesis. The Arabidopsis ipt1,3,5,7 quadruple mutant completely lacks cambial activity, but this can be rescued by treatment with exogenous cytokinin (Miyawaki et al., 2006; Matsumoto-Kitano et al., 2008). Moreover, the expression of a cytokinin catabolic gene in Populus alba (poplar) led to a remarkable decrease in cambial cell divisions and thinner trunks (Immanen et al., 2016). By contrast, increasing cytokinin levels in poplar stems by overexpressing IPT7 under the wood-specific LMX5 promoter strongly stimulated cambial cell division and biomass production (Immanen et al., 2016). In addition, it was shown that secondary growth in Arabidopsis thaliana (Arabidopsis) roots is dependent on the cytokinin-responsive transcription factor AINTEGUMENTA (ANT) and the D-type cyclin CYCD3;1, which are both expressed in the vascular cambium (Dewitte et al., 2007; Randall et al., 2015). Although a positive role for cytokinin signaling in cambial stem cell activity has been demonstrated, it is still largely unknown how cytokininsignaling promotes cambial activity.

Here we identified a new role for the Arabidopsis AT-HOOK MOTIF CONTAINING NUCLEAR LOCALIZED 15 (AHL15) gene as an important regulator of vascular cambial activity and secondary xylem formation. AHL15 is part of a plant-specific protein family, containing a single AT-hook DNA binding motif and a Plant and Prokaryote Conserved (PPC) domain (Fujimoto et al., 2004; Zhao et al., 2013). AHL15 homologs have been implicated in several aspects of plant growth and development in Arabidopsis, including flowering time and hypocotyl growth (Street et al., 2008; Xiao et al., 2009), flower development ( $\mathrm{Ng}$ et al., 2009), vascular tissue differentiation (Zhou et al., 2013), and gibberellin biosynthesis (Matsushita et al., 2007). In addition, we have recently shown that AHL15 and family members play key roles in plant embryogenesis (Karami et al., 2020b) and -longevity (Karami et al., 2020a). Apart from promoting plant longevity, we also discovered that AHL15 enhances secondary growth. A more detailed analysis indicated that AHL15 is a central regulator of vascular cambium activity in Arabidopsis thaliana (Arabidopsis) that links the action of the upstream flowering genes SOC1 and FUL to the downstream cytokinin biosynthesis genes IPT3, IPT7 and LOG4. 


\section{Results}

\section{AHL15 promotes secondary growth in Arabidopsis inflorescence stems}

In contrast to woody plants that already produce a ring of xylem in young inflorescence stems, herbaceous plants, such as Arabidopsis, produce only a limited amount of xylem without forming a xylem ring in young stems. Secondary growth does occur in older Arabidopsis inflorescence stems and is generally quantified by the number of secondary xylem cell files produced by cambial cell divisions in the interfascicular part of the stem (the area between two bundles) (Nieminen et al., 2015; Fischer et al., 2019). In the Arabidopsis soc1 ful double loss-of-function mutant, however, xylem formation is significantly enhanced, resulting in the formation of a xylem ring even in young inflorescence stems (Melzer et al., 2008). In addition, socl ful mutant plants show extended longevity by the maintenance of vegetative growth from axillary meristems (AMs) (Melzer et al., 2008).

Recently, we have shown that overexpression of the Arabidopsis AHL15 gene (p35S:AHL15) also increases plant longevity (Fig. 1A), similar to socl ful plants, and that AHL15 acts downstream of the SOC1 and FUL transcription factors in maintaining AMs in the vegetative phase (Karami et al., 2020a). In view of these data, we analyzed whether AHL15 overexpression could also promote secondary growth and xylem formation in p35S:AHL15 inflorescence stems. One-month-old $p 35 S$ :AHL15 stems displayed a significant increase in xylem formation compared to wild-type stems (Fig. 1B). In 2- and 3-month-old p35S:AHL15 stems secondary xylem formation continued, whereas it stopped in 2-month-old wild-type stems (Fig. 1B, C). These results suggested that AHL15 can trigger cambium activity and thereby enhance secondary growth in Arabidopsis inflorescence stems. Arabidopsis inflorescence stems normally produce more secondary xylem than secondary phloem (Altamura et al., 2001).

Lignin staining showed that inflorescence stems of one-month-old p35S:AHL15 plants produced more lignified xylem cells in the interfascicular region than those of wild-type plants (Fig. 1E, F). In contrast, ahl15 loss-of-function mutant stems contained significantly less lignified xylem cells at interfascicular region than wild-type stems (Fig. 1E, F), even though ahl15 plants developed and flowered like wild-type plants (Fig. 1D). Introduction of the pAHL15:AHL15 genomic clone into the ahl15 mutant background completely restored the secondary xylem growth to wild-type levels (Fig. 1E, F), indicating that the reduction in the xylem cell number was caused by ahl15 loss-of-function.

Previous studies have shown that expression of a mutant AHL protein (AHL15- $\Delta \mathrm{G}$ ), from which the conserved six amino-acid sequences (GRFEIL) in the PPC domain was deleted, in the heterozygous ahl15/+ mutant background leads to a dominant-negative effect that overcomes the functional redundancy between the different $A H L$ family members (Zhao et al., 2013; Karami et al., 2020a). Whereas pAHL15:AHL15- $\triangle G$ plants showed wild-type development, as previously reported (Karami et al., 2020a), ahl15/+ pAHL15:AHL15- $A G$ plants developed even less secondary xylem (Fig. 1D) compared to ahl15 plants (Fig. 1E, F). The diameter of ahl15 stems was already smaller than wild-type stems, but ahl15/+ pAHL15:AHL15- $\triangle G$ stems remained even smaller in size (Supplementary Figure 1). Except for the difference in cambium activity, mutant stems showed the same structure and tissue organization as wild-type stems (Supplementary Figure 2). These results show that AHL15 
bioRxiv preprint doi: https://doi.org/10.1101/2020.06.19.162297; this version posted June 20, 2020. The copyright holder for this preprint (which was not certified by peer review) is the author/funder. All rights reserved. No reuse allowed without permission.

plays an important role in increasing cambium activity and secondary growth in Arabidopsis inflorescence stems, and that like with developmental processes such as embryogenesis and AM maturation (Karami et al., 2020a, 2020b), it acts partially redundant with other $A H L$ genes.
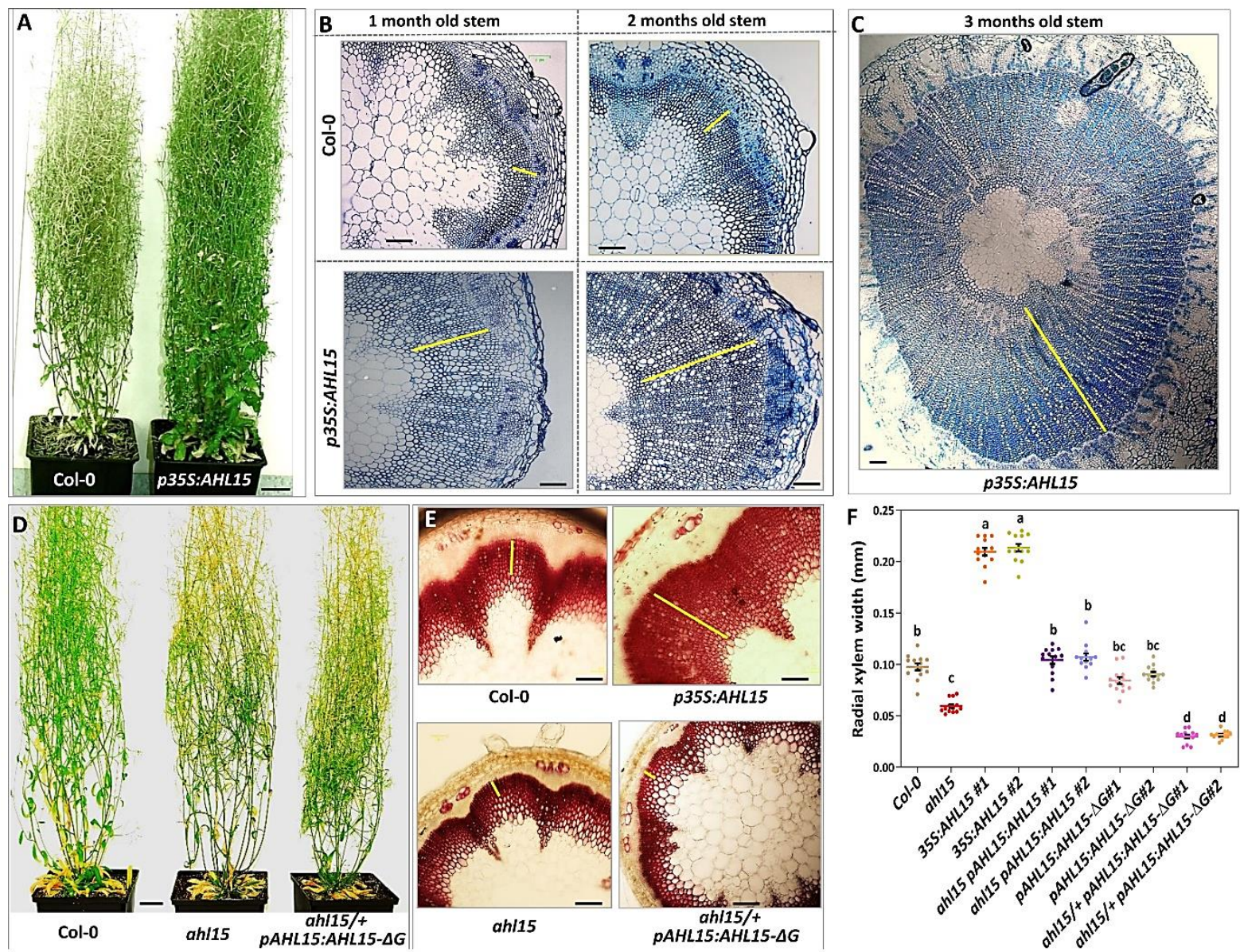

Fig. 1| AHL15 promotes secondary growth in Arabidopsis inflorescence stems. (A) Plant shoot phenotype of a three-month-old wild-type and p35S:AHL15 plants. (B) Toluidine blue-stained cross-sections of mostbottom base of a one-month-old (left panel) or two-month-old (right panel) inflorescence stem of wild-type and p35S:AHL15 Arabidopsis plants. (C) Toluidine blue-stained cross-sections of most-bottom base of a threemonth-old p35S:AHL15 inflorescence stem. (D) Shoot phenotypes of two-month-old wild-type (left), ahl15 (middle) and ahl15/+ pAHL15:AHL15- $\triangle G$ mutant (right) plants. (E) Phloroglucinol-stained fresh cross-sections of most-bottom base of a one-month-old wild-type (upper panel left), p35S:AHL15 (upper panel right), ahl15 (lower panel left), and ahl15/+ pAHL15:AHL15-AG (lower panel right) inflorescence stems. (F) Quantification of the secondary xylem width (most-bottom base) in interfascicular part of one-month-old wild-type, p35S:AHL15, ahl15 and pAHL15:AHL15 ahl15,pAHL15:AHL15- $\triangle G$ and ahl15/+ pAHL15:AHL15- $A G$ main inflorescence stems. Colored dots indicate the average secondary xylem width of 3 random interfascicular region of an individual stem independent plants $(n=9)$, all the secondary xylem width are presenting the width average per line, horizontal lines indicate the mean and error bars indicate the s.e.m. Different letters indicate statistically significant differences $(\mathrm{P}<0.01)$ as determined by a one-way ANOVA with Tukey's honest significant difference post hoc test. The yellow bars in (B), (C) and (E) mark the xylem width in the interfascicular cell domain. Scale bars indicate $2 \mathrm{~cm}$ in (A) and (D) and $0.06 \mathrm{~mm}$ in (B), (C) and (E). 

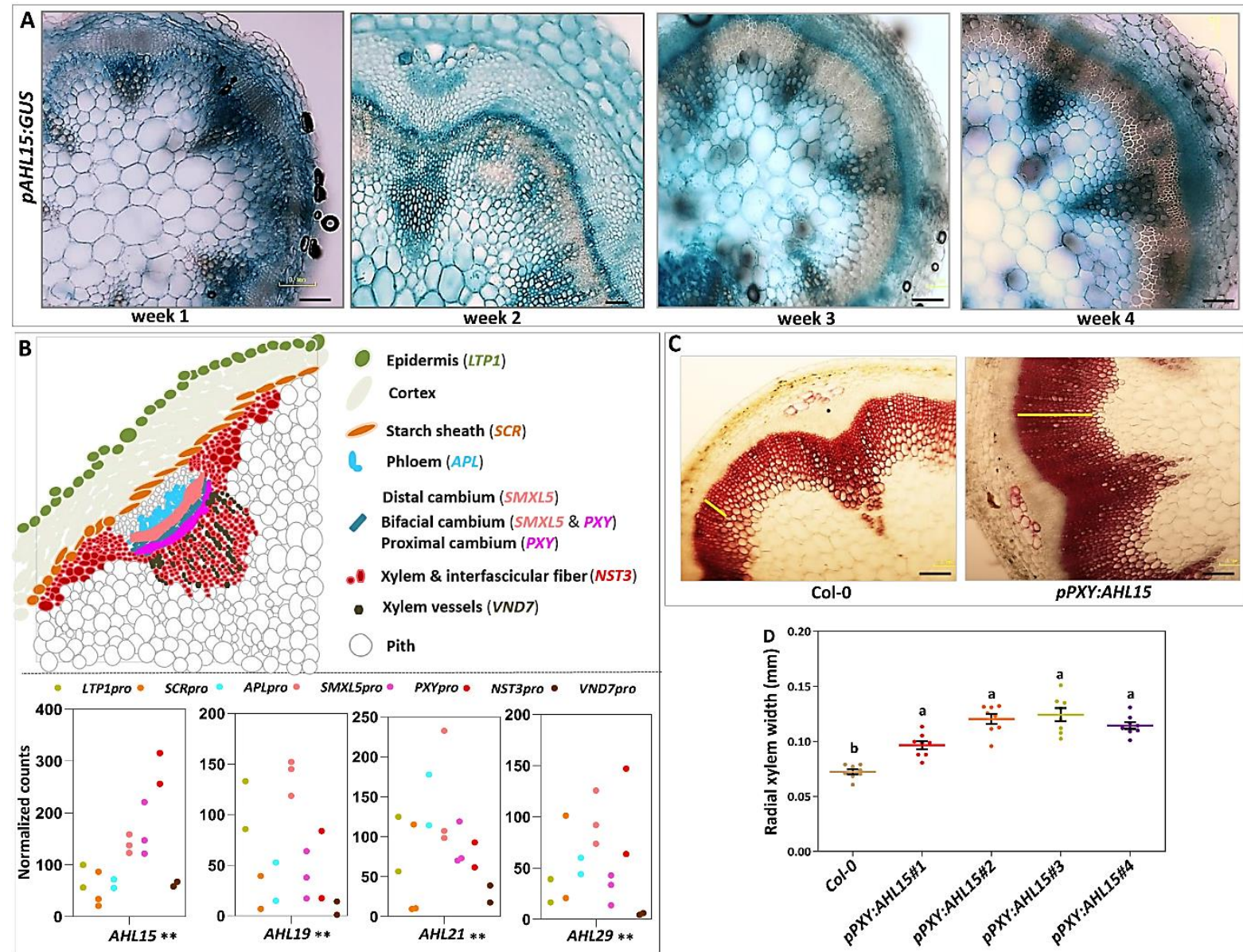

Fig. 2| Along with unique expression pattern of $A H L 15$ in cambium area with other $A H L s$, Cambiumspecific $A H L 15$ expression promotes secondary xylem formation (A) Cross-sections of most-bottom base of a one-,two-, three- and four-week-old inflorescence stems presenting the expression pattern the pAHL15:GUS reporter line (promoter activity). (B) Schematic representation of part of a cross section of an inflorescence stem, including the vascular bundle and the interfascicular regions, in which different stem tissues and the tissue-specific expression domains of genes used for stem transcriptome profiling are indicated (NST3 (fibers), VND7(xylem vessels), $P X Y$ (proximal cambium), SMXL5 (distal cambium), APL (phloem), SCR(starch sheath), LTP1(epidermis cells) (upper panel) ). Co-expression of AHL15, AHL19, AHL21 and AHL29 genes at cambium and bundle domains. (lower panel). Normalized read counts of the $A H L$ genes in the tissue-specific gene expression atlas generated by combining fluorescence-activated nucleus sorting (FANS) using the promoter-H4GFP fusions of the indicated marker genes (NST3, VND7, PXY, SMXL5, APL, SCR and LTP1) and combining FANS and laser-capture microdissection with next generation RNA sequencing (Shi et al., 2020). Colored dots indicate the values of two or three biological replicates of RNA isolation obtain by FANS, Normalized gene read counts of the indicated genes among seven different tissues displayed for each replicate individually. *, ** indicates $\mathrm{p}<0.05$ and 0.01, respectively in LRT (Shi et al., 2020). (C) Phloroglucinol-stained fresh crosssections of most-bottom base of a one-month-old wild-type (left) and $p P X Y$ :AHL15 (right) inflorescence stems. The yellow bars mark the xylem width in the interfascicular cell domain. (D) Quantification of the secondary xylem width (most-bottom base) in interfascicular part of one-month-old wild-type and pPXY:AHL15 main inflorescence stems. ( 5 individual lines). Colored dots indicate the average secondary xylem width of 3 random interfascicular region of an individual stem independent plants $(n=7)$, all the secondary xylem width are presenting the width average per line, horizontal lines indicate the mean and error bars indicate the s.e.m. Different letters indicate statistically significant differences $(\mathrm{P}<0.01)$ as determined by a one-way ANOVA with Tukey's honest significant difference post hoc test. Scale bars in (A) and (C) indicate $0.06 \mathrm{~mm}$. 


\section{SOC1/FUL-repressed cambium-specific $A H L 15$ expression regulates secondary growth}

The above results suggested that $A H L 15$ is expressed in the vascular cambium area where it regulates cambial cell division activity. Histochemical staining of plants having the AHL15 promoter $\beta$-glucuronidase (GUS) reporter ( $p A H L 15: G U S)$ in wild-type background indicated that AHL15 is expressed in almost all tissues in 1-week-old inflorescence stems (1-week after bolting) (Fig. 2A), but that the expression became progressively restricted to the vascular and interfascicular cambium zone during stem maturation (Fig. 2A). Interestingly, AHL15 expression was completely absent from the secondary xylem, whereas it remained expressed in the primary xylem and xylem fibers of the inflorescence stem (Fig. 2A).

In order to confirm that $A H L 15$ is expressed in the vascular cambium, we extracted the expression pattern of clade-A $A H L$ genes from tissue-specific gene expression atlas generated from different Arabidopsis stem tissues (e.g., xylem vessels, fibers, the proximal and the distal cambium, phloem, phloem cap, pith, starch sheath, and epidermis cells; see Fig. 2B) by combining fluorescence-activated nucleus sorting and laser-capture microdissection with next-generation RNA sequencing (Shi et al., 2020). The extracted AHL15 expression from this data belonging to the second bottom-most internode of Arabidopsis stem (about 2 weeks after bolting) (Fig. 2B) showed a high level of similarity with the activity pattern of the pAHL15:GUS reporter in 2-week-old inflorescence stem up to 4-week old stems. The expression of AHL15 in the PXY and SUPPRESSOR OF MAX2 1-LIKE PROTEIN 5 (SMXL5) cambium sub-domains, the areas where cell division is taking place (Shi et al., 2019), further supported the role of AHL15 in promoting vascular cambium activity. In line with the functional redundancy between $A H L$ genes in promoting cambium activity, we also found AHL19, AHL20, and AHL29 to be expressed in the PXY and SMXL5 cambium subdomains (Fig. 2B).

Altogether, the seemingly overlapping expression of $A H L$ genes in the stem cambium zone supports their role in the regulation of cambium activity. To establish whether $A H L$ expression in the Arabidopsis vascular cambium is rate-limiting for secondary growth, we expressed AHL15 under control of the cambium-specific PXY promotor ( $P P X Y: A H L 15$ ) (Fisher and Turner, 2007). Lignin stained one-month-old $p P X Y: A H L 15$ stems showed a significant increase in secondary xylem development compared to wild-type stems (Fig.2 C, D). These results indicate that in wild-type Arabidopsis, secondary growth and xylem development are limited by $A H L$ expression, and that cambium-specific enhancement of AHL15 expression is sufficient to promote cambium activity. Apart from the enhanced cambium activity, $p P X Y$ :AHL15 plants developed and flowered like wild-type plants (Supplementary Figure 3), confirming that the effect of locally enhanced AHL15 expression on cambium activity is direct, and not caused by changes in developmental timing.

Previously, we have shown that AHL15 expression is repressed by binding of the SOC1 and FUL MADS-box transcription factors to its up- and downstream genomic regions, and that alleviation of this repression in the socl ful double mutant leads to delayed maturation of AMs, resulting in the mutant aerial rosette phenotype (Karami et al., 2020a). Comparison of socl ful double mutant with socl ful ahl15 triple mutant stems showed that the high secondary xylem production in soc 1 ful stems was dependent on the presence of a functional AHL15 gene. The interfascicular secondary xylem formation was reduced to wild-type levels in the socl ful ahl15 triple mutant (Fig. 3A, B). This is in line with the previously observed 
bioRxiv preprint doi: https://doi.org/10.1101/2020.06.19.162297; this version posted June 20, 2020. The copyright holder for this preprint (which was not certified by peer review) is the author/funder. All rights reserved. No reuse allowed without permission.

enhanced expression of AHL15 in socl ful mutant AMs (Karami et al., 2020a). The coexpression of AHL15 with SOC1 and FUL in the PXY and SMXL5 cambium sub-domains (Fig. 3C) further supports the negative regulation of $A H L 15$ by $S O C 1$ and $F U L$ in cambium related domains, which limits secondary growth in the herbaceous wild-type Arabidopsis.
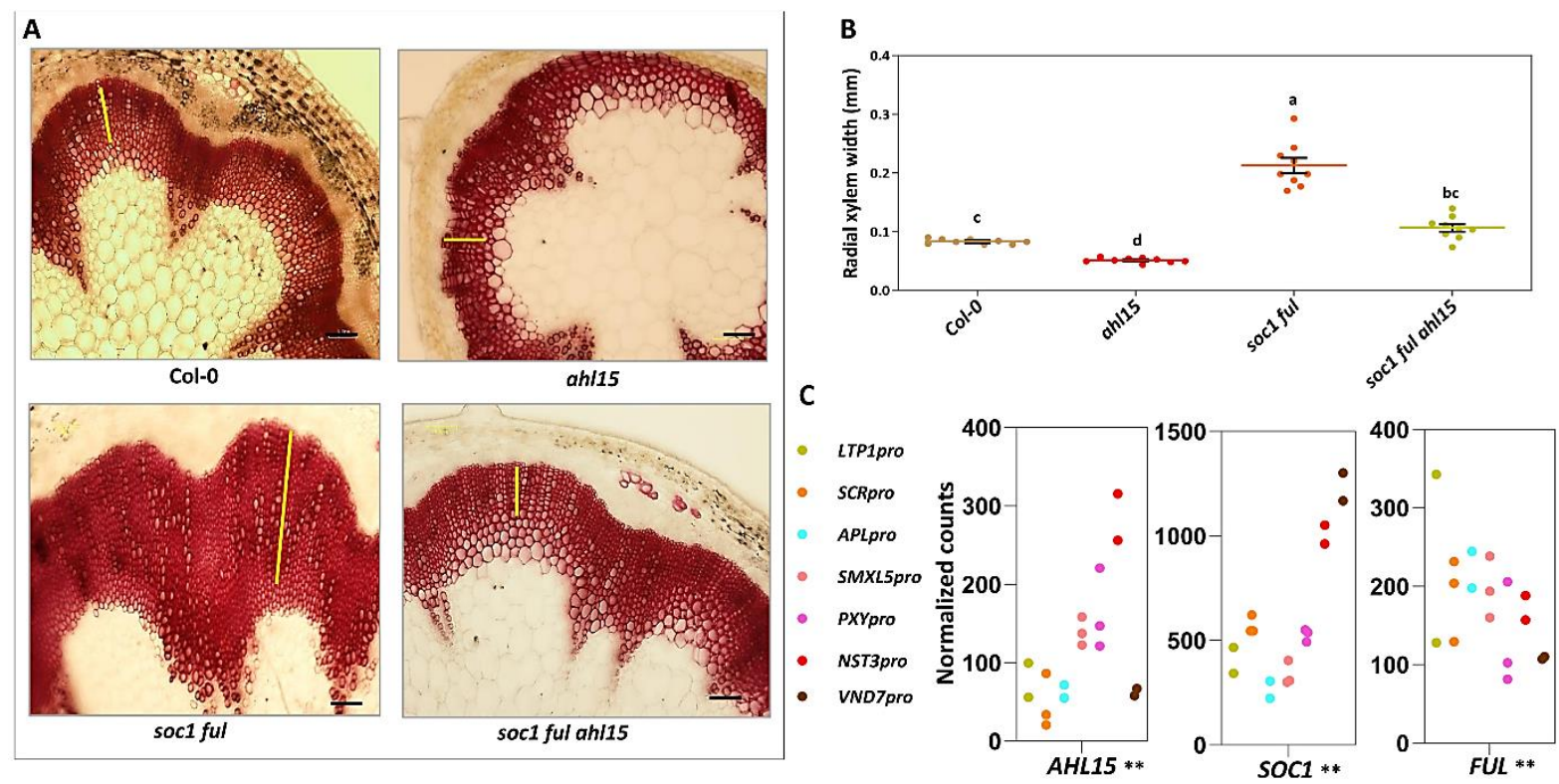

Fig. 3| AHL15 is required for enhanced secondary xylem formation in the soc1 ful double mutant. (A) Phloroglucinol-stained fresh cross-sections of most-bottom base of a one-month-old wild-type (upper panel, left), ahl15 (upper panel, right), soclful (lower panel, left) and soclful ahl15 (lower panel, right) inflorescence stems. The yellow bars mark the xylem width in the interfascicular cell domain. (B) Quantification of the secondary xylem width (most-bottom base) in interfascicular part of one-month-old wild-type, ahl15, soclful and soclful ahl15 main inflorescence stems. Colored dots indicate the average secondary xylem width of 3 random interfascicular region of an individual stem independent plants $(n=9)$, all the secondary xylem width are presenting the width average per line, horizontal lines indicate the mean and error bars indicate the s.e.m. Different letters indicate statistically significant differences $(\mathrm{P}<0.01)$ as determined by a one-way ANOVA with Tukey's honest significant difference post hoc test. (C) Co-expression of AHL15, SOC1 and FUL genes at cambium and bundle domains. Colored dots indicate the values of two or three biological replicates of RNA isolation obtain by FANS. Normalized gene read counts of the indicated genes among seven different tissues displayed for each replicate individually. *, ** indicates $\mathrm{p}<0.05$ and 0.01 , respectively in LRT (Shi et al., 2020). Scale bars indicate $0.06 \mathrm{~mm}$. 


\section{AHL15 promotes secondary growth by increasing cytokinin biosynthesis}

In Arabidopsis inflorescence stems, secondary growth is initiated by the occurrence of interfascicular cambium, leading to the formation of a cambium ring. The initial cell divisions marking the starting point of interfascicular cambium formation can be readily observed in one-week-old wild-type stems, but are absent in one-week-old ahl15 loss-offunction stems (a noticeable feature of this mutant), despite a normal organization of the mutant stem tissues (Fig. 4A). In contrast, one-week-old p35S:AHL15 inflorescence stems already showed a cambium ring consisting of several layers of cells in the interfascicular region (Fig. 4A). These results indicate an important role for AHL15 in cambium initiation and the promotion of cambial cell divisions. Previous studies have highlighted that the cell division rate in the procambium and cambium is regulated by the plant hormone cytokinin (Matsumoto-Kitano et al., 2008; Immanen et al., 2016). To test the involvement of cytokinin in the AHL15-enhanced cell divisions, we compared the expression of cytokinin response reporter pTCS:GFP (Zürcher et al., 2013) in wild-type, ahl15 or p35S:AHL15 inflorescence stems during cambium development. In very young (2-day-old) stems, only a weak pTCS:GFP expression could be detected in the procambium zone of stems of all three genetic backgrounds, indicating that AHL15 does not modulate the cytokinin response in these very young stems stage (Fig.4B, left images). However, three days later, when $p T C S: G F P$ signals started to appear in the interfascicular regions of wild-type stems, $p T C S: G F P$ expression was still limited to the procambium in ahl15 stems, whereas p35S:AHL15 stems displayed a ring of pTCS:GFP signal colocalizing with the cambium ring already present in these stems (Fig. $4 \mathrm{~B}$, middle images). These overlapping rings of cambium and pTCS:GFP expression also became visible in 10-day-old wild-type stems, and were even stronger in p35S:AHL15 stems (Fig.4B, right images). In 10-day-old ahl15 stems, however, pTCS:GFP expression remained restricted to the cambium in the vascular bundles (Fig.4B, right images). These results suggested that AHL15 might regulate cambium initiation and promote the cambial cell division rate in Arabidopsis stems by altering cytokinin biosynthesis or -response.

To analyze the effect of AHL15 on cytokinin biosynthesis, the expression of the cytokinin biosynthesis genes IPT7, IPT3, LONELY GUY4 (LOG4) and LOG5 (Matsumoto-Kitano et al., 2008) was compared between wild-type and ahll5 mutant stems. Our qPCR experiments showed that the expression of IPT3, IPT7, and LOG4 was significantly reduced in ahl15 stems (Fig. 4C), suggesting that AHL15 acts by activating these cytokinin biosynthesis genes in the cambium area. This was further confirmed by the co-expression of AHL15, IPT3, IPT7, LOG4, and LOG5 in the PXY and SMXL5 cambium sub-domains (Supplementary Fig. 4).

To verify that the reduced secondary xylem formation in ahll5 mutant stems was caused by a reduced cytokinin biosynthesis, we introduced the Agrobacterium tumefaciens IPT gene under the control of the cambium-specific PXY promoter ( $p P X Y: I P T)$ in the ahl15 mutant background (Robson et al., 2004; Van Der Graaff et al., 2001). The presence of the $p P X Y: I P T$ construct significantly increased the width of interfascicular lignified xylem in ahl15 stems, bringing it back to wild-type or even higher levels (Fig. 4D-E). Our data demonstrate that local expression of AHL15 assisted by that of redundantly acting $A H L$ genes determines the initiation and activity of interfascicular cambium and thereby the secondary growth of Arabidopsis inflorescence stems by promoting cytokinin biosynthesis. 
bioRxiv preprint doi: https://doi.org/10.1101/2020.06.19.162297; this version posted June 20, 2020. The copyright holder for this preprint (which was not certified by peer review) is the author/funder. All rights reserved. No reuse allowed without permission.
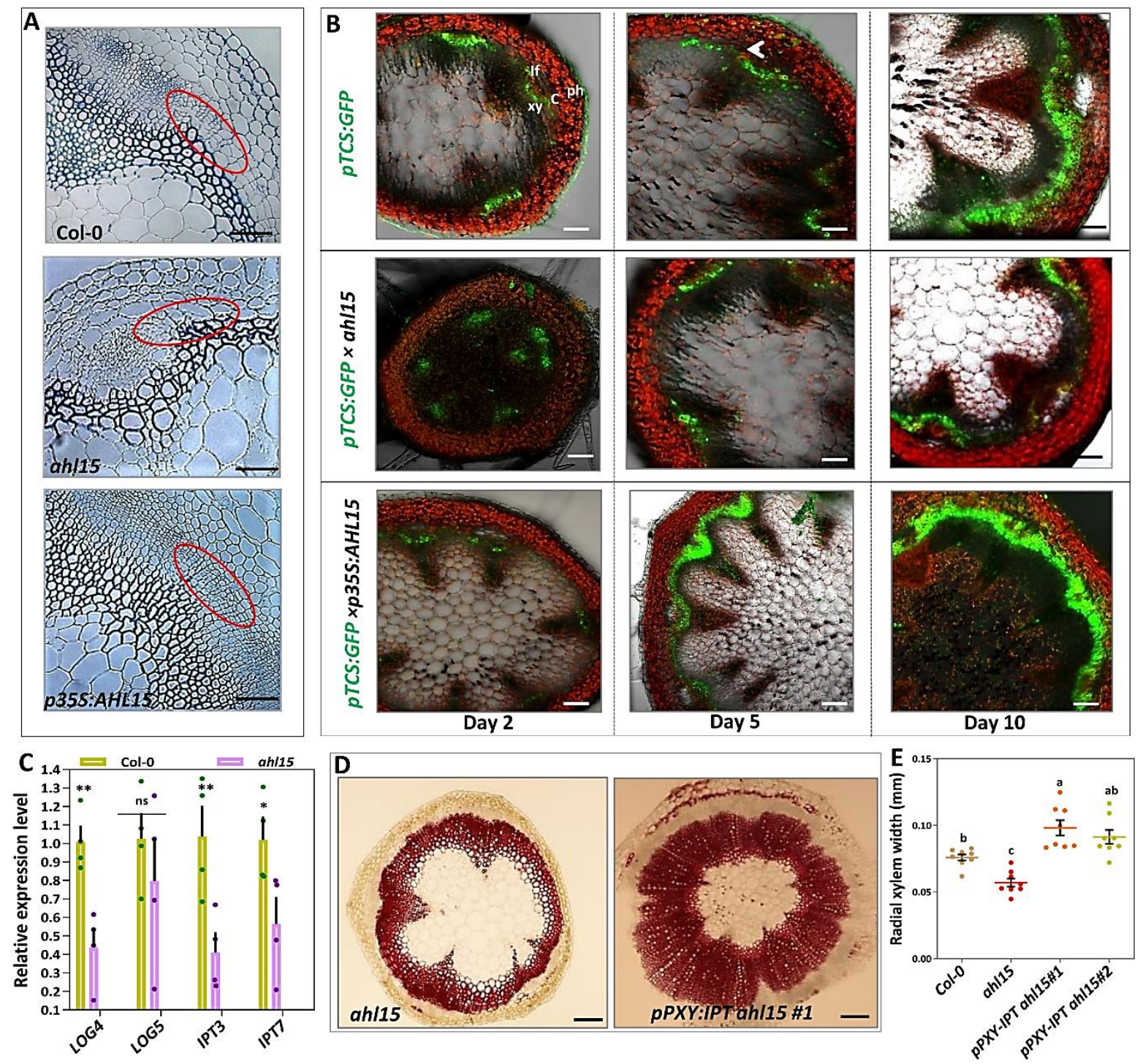

Fig. 4| Cytokinin acts downstream of $\boldsymbol{A H L 1 5}$ to promote cambium activity. (A) Toluidine blue-stained cross-sections of most-bottom base of one-week-old wild-type (upper), ahl15 (middle) and p35S:AHL15 (lower) inflorescence stems. The red circle marks the cambium cell division area in the interfascicular region which is absent in ahl15 mutant. (B) Confocal images showing the expression of the pTCS:GFP cytokinin response reporter cross-sections of most-bottom base of two-, five- and ten-day-old wild-type (upper panel)(arrow indicate the cambium cell division start point in wild-type), ahl15 (middle panel) and p35S:AHL15 (lower panel) inflorescence stems. (C) Relative expression of the cytokinin biosynthesis genes LOG4, LOG5, IPT3 and $I P T 7$ by qPCR analysis in the base of ten-day-old wild-type and ahll5 inflorescence stems. Dots indicate the values of three biological replicates per plant line, bars indicate the mean and error bars indicate the s.e.m. Asterisks indicate significant differences between wild-type and ahl15 plants $(* \mathrm{P}<0.05, * * \mathrm{P}<0.01$, ns (not significant)), as determined by a two-sided Student's $t$-test. (D) Phloroglucinol-stained fresh cross-sections of most-bottom base of one-month-old ahl15 (left) and ahl15 pPXY:IPT (right) inflorescence stems. (E) Quantification of the secondary xylem width (most-bottom base) in interfascicular part of one-month-old wildtype, ahl15 and ahl15 pPXY:IPT (2 independent lines) main inflorescence stems. Colored dots indicate the average secondary xylem width of 3 random interfascicular region of an individual stem independent plants $(n=$ 9), all the secondary xylem width are presenting the width average per line, horizontal lines indicate the mean and error bars indicate the s.e.m. Different letters indicate statistically significant differences $(\mathrm{P}<0.01)$ as determined by a one-way ANOVA with Tukey's honest significant difference post hoc test. Scale bars indicate $0.05 \mathrm{~mm}$ in $\mathrm{A}, \mathrm{B}$ and $0.15 \mathrm{~mm}$ in $\mathrm{D}$. 


\section{AHL15 promotes secondary growth independent of the PXY-WOX pathway}

In Arabidopsis inflorescence stems, the WUSCHEL HOMEOBOX RELATED 4 (WOX4) and WOX14 genes have been shown to promote the rate of cell division in the vascular cambium (Denis et al., 2017; Etchells et al., 2013; Campbell et al., 2016). Inflorescence stems from the wox4 wox14 double mutant develop significantly less secondary xylem in the interfascicular regions (Etchells et al., 2013). In view of the co-expression of WOX4, WOX14, and AHL15 in the PXY and SMXL5 cambium sub-domains (Fig. 5A) and the fact that loss-of-function mutant inflorescence stems show similar defects in cambium development, we investigated the genetic interaction between AHL15 and WOX4/WOX14 in controlling secondary xylem growth. Introduction of $p P X Y$ :AHL15 into the wox4 wox14 pxy mutant background did not lead to enhanced secondary growth (Fig. 5B, C). This result indicated that AHL15 is not responsible for promoting cell division downstream of WOX4 and WOX14, but instead that the PXY-WOX4/14 pathway is required for AHL15 action. However, the $p$ WOX4:GFP reporter, which normally labels the vascular bundles and the cambium cells in wild-type stems (Suer et al., 2011), did not show a clear difference in ahl15 mutant inflorescences stems, indicating that the WOX genes are not downstream of AHL15 (Fig. 5 D). Based on these experiments, we conclude that PXY-WOX and AHL15-IPT are parallel pathways that are mutually required to promote cell division in the interfascicular cambium of Arabidopsis inflorescence stems. 
bioRxiv preprint doi: https://doi.org/10.1101/2020.06.19.162297; this version posted June 20, 2020. The copyright holder for this preprint (which was not certified by peer review) is the author/funder. All rights reserved. No reuse allowed without permission.

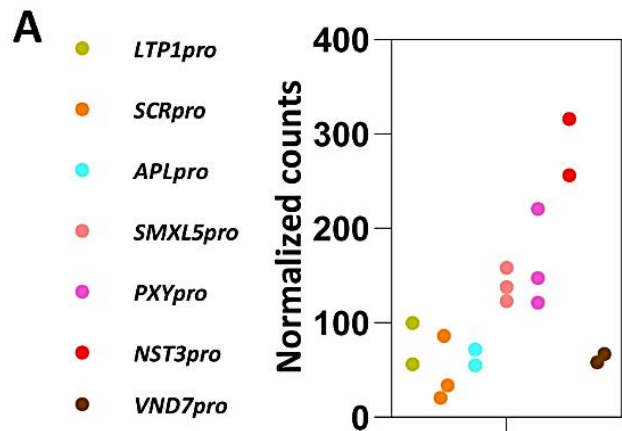

AHL15**

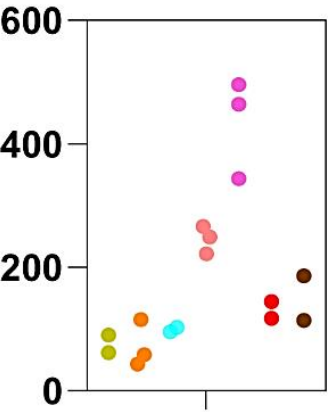

WOX4 **

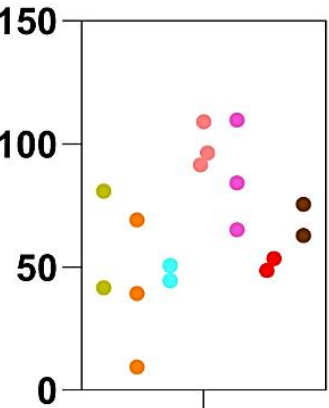

WOX14 **
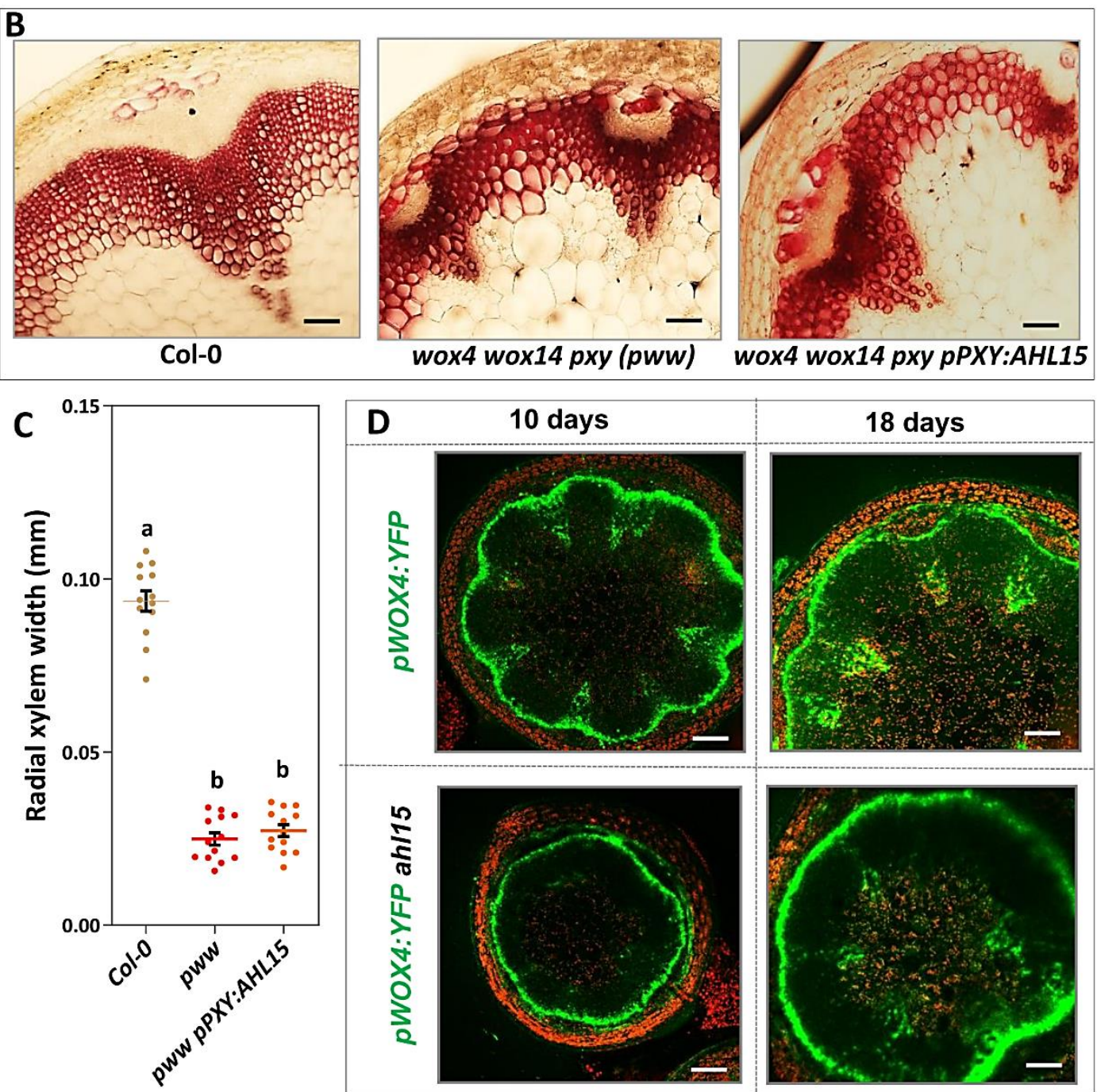

Fig. 5| $A H L 15$-cytokinin and $P X Y$-WOX4,14 represent two parallel pathways regulating cambium activity. (A) Co-expression AHL15, WOX4 and WOX14 at cambium and bundle domains. Colored dots indicate the values of two or three biological replicates of RNA isolation obtain by FANS. Normalized gene read counts of the indicated genes among seven different tissues displayed for each replicate individually. ${ }^{*}, * *$ indicates $\mathrm{p}<$ 0.05 and 0.01, respectively in LRT (Shi et al., 2020). (B) Phloroglucinol-stained fresh cross-sections of mostbottom base of one-month-old wild-type (left) and pxy wox4 wox14 (middle) and pPXY:AHL15 pxy wox4 wox14 (right) inflorescence stems. (C) Quantification of the secondary xylem width (most-bottom base) in interfascicular part of one-month-old wild-type, pxy wox4 wox14 ( $p w w)$ and pPXY:AHL15 pxy wox4 wox14 main inflorescence stems. Colored dots indicate the average secondary xylem width of 3 random interfascicular region of an individual stem independent plants $(\mathrm{n}=12)$, all the secondary xylem width are presenting the width 
average per line, horizontal lines indicate the mean and error bars indicate the s.e.m. Different letters indicate statistically significant differences $(\mathrm{P}<0.01)$ as determined by a one-way ANOVA with Tukey's honest significant difference post hoc test. (D) Confocal analyses shows activity of $p W O X 4-G F P$ at 10 and 18-day-old wild-type (up panel) and ahl15 (low panel) stem. Scale bars indicates $0.06 \mathrm{~mm}$ in B and $0.09 \mathrm{~mm}$.

\section{Discussion}

Understanding the molecular mechanisms regulating the activity and functioning of vascular cambium is fundamentally important because the woody biomass in plants derives from the activity of the vascular cambium. The cell division rate of the stem cells of the vascular cambium plays a crucial role in secondary growth: how active the stem cells are in the cambial zone can determine the amount of secondary growth or wood formation (Campbell et al., 2016; Chiang and Greb, 2019). Although previous studies have provided the first insight into the molecular basis regulating cambial activity, our fundamental insight into how initiating and regulated cambial stem cell activity has remained largely unknown.

In this study, we present the role of AHL15 as a novel regulator in the control of interfascicular cambium activity and secondary xylem formation in Arabidopsis. In particular, in inflorescence stems of ahl15 loss-of-function mutant plants, we observed a delay in cambium initiation and formation from parenchyma cells and a significant reduction in the amount of secondary xylem formed. By contrast, inflorescence stems of AHL15 overexpression plants developed an increased amount of secondary xylem. Our data suggest that the AHL15 gene is a positive regulator of cambial cell proliferation and thereby an important determinant of secondary xylem formation in Arabidopsis inflorescence stems.

AHL15 belongs to a large family of $A H L$ genes in Arabidopsis that have a high degree of functional redundancy among family members (Xiao et al., 2009; Zhao et al., 2013). In line with our recent observations on the redundant action of AHL15 and other AHL genes in controlling axillary meristem maturation (Karami et al., 2020a), and embryogenesis (Karami et al., 2020b), the results presented here suggest that $A H L$ genes also act redundantly in regulating interfascicular cambium activity. The overlapping expression of $A H L 15, A H L 19$, AHL20, and AHL28 in the PXY/SMXL5-marked cambium region of inflorescence stems is in line with their redundant role in controlling cambial cell proliferation. Despite this redundancy, and as observed for axillary meristem maturation (Karami et al., 2020a), AHL15 seems to play a key role in this process, since secondary growth is significantly reduced in the ahl15 loss-of-function mutant background.

The cell division in the cambial zone is known to be controlled by both genetic and hormonal factors (Immanen et al., 2016; Oles et al., 2017; Fischer et al., 2019). Based on the current model, the TDIF-PXY-WOX and cytokinin/auxin pathways act in parallel to regulate cell division in the vascular cambium (Fig. 6) (Fischer et al., 2019). In the first pathway, the TDIF peptide, belonging to the CLE family of peptides, is produced in the phloem and subsequently transferred to the cambium where it binds to the PXY receptor-like kinase. Upon peptide binding, PXY activates the expression of the cambium-specific transcription factors WOX4 and WOX14, which promote cell proliferation in the cambium (Fig. 6). Our results show that AHL15 promotes the timing of cambial cell initiation, proliferation, and 
maintenance afterward in parallel to and dependent on the TDIF-PXY-WOX pathway by increasing the expression of cytokinin biosynthesis genes (Fig. 6). Interestingly, it has been shown that the cambial cell division and secondary xylem production are significantly increased upon elevated cytokinin levels in the stem of poplar trees (Immanen et al., 2016). We have previously shown that the MADS-box transcription factors SOC1 and FUL repress AHL15 expression by directly binding to the AHL15 upstream and downstream regions (Karami et al., 2020a). In addition, we show here that the enhanced secondary growth in the socl ful double mutant inflorescence stems is dependent on the presence of a functional AHL15 gene, indicating that SOC1 and FUL also act as repressors of secondary growth upstream of AHL15 (Fig. 6). We conclude that PXY-WOX and SOC1/FUL-AHL15-IPT are parallel pathways that are mutually required to promote cell division in the interfascicular cambium of Arabidopsis inflorescence stems.

It has been reported that AHL3-AHL4 heterodimers control the boundary between the procambium and xylem axis in Arabidopsis roots (Zhou et al., 2013). Single and double lossof-function mutants of $A H L 3$ and AHL4 display ectopic protoxylem vessels and ectopic metaxylem vessels in the procambial region adjacent to the xylem axis (Zhou et al., 2013). Since the cytokinin response is altered in the ahl4 loss-of-function mutant and similar vascular defects have been observed for cytokinin-defective mutants (Zhou et al., 2013), this confirms the strong relationship between $A H L$ genes and cytokinin in cambium initiation and cell division, and in the resulting xylem formation.

How exactly cytokinin promotes cambial cell divisions is still not understood. Cytokinin likely influences the cell cycle of the cambium stem cells. Because cytokinin and auxin usually work together, cytokinin may exert its effect on the cambial cell division by reducing the concentration of auxin in cambium cells by up-regulating the levels of PIN auxin efflux carriers (Duclercq et al.,2009; Šimášková et al., 2015). However, this should be confirmed by future studies.

In conclusion, our studies show that $A H L$ genes positively regulate both cambium activity and axillary meristem outgrowth in Arabidopsis, downstream of the SOC1 and FUL transcription factors and upstream of cytokinin biosynthesis. Our findings represent an important step forward in our understanding of the increased vascular cambium activity in soc1 ful mutant plants. In particular, our findings show that it is possible to increase secondary growth without affecting the flowering time and fruit and seed development of plants, which will eventually be helpful for plant biomass improvement. 


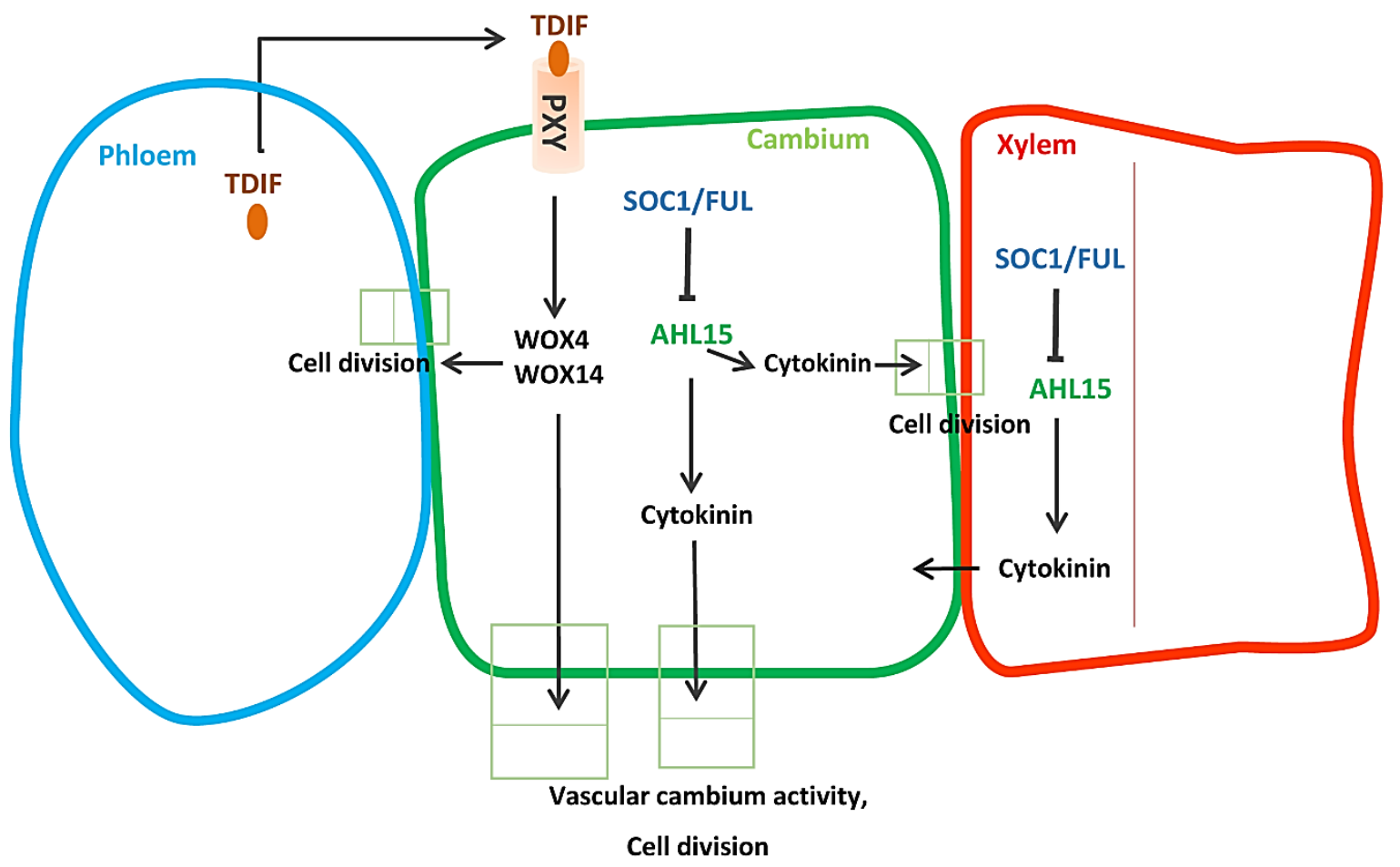

Fig. 6| Proposed model for $\boldsymbol{A H L 1 5}$ and its key role in promoting cambium activity. Close up of cambium area with different units include phloem (blue), cambium (green), and xylem (red). Peptide TDIF is synthesized in the phloem, travels through the apoplastic space to cambium cells, where it binds to its receptor PXY. PXY subsequently promotes the proliferation of the cambium cells by activating the expression of WOX4 and WOX14. In a parallel pathway, AHL15 promotes cambium activity independent of PXY-WOX and in downstream of SOC1 and FUL and upstream of cytokinin biosynthesis either in cambium cells or in xylem. Blunt-ending lines indicate repression, arrows indicate promotion.

\section{Methods}

\section{Plant material, growth conditions, and transgenic Arabidopsis lines}

All Arabidopsis mutant- and transgenic lines used in this study are in the Columbia (Col-0) background. The ahl15 mutant and the pAHL15:AHL15, pAHL15:GUS, ahl15/+ pAHL15:AHL15- $\triangle G$ transgenic lines (Karami et al., 2020a) and the $p 35 S: A H L 15$ transgenic line (Karami et al., 2020a) were previously described. The soc1-6 ful-7 double mutant (Melzer et al., 2008), the pxy wox4 wox 14 mutant and the pTCS:GFP (Bruno and Jen, 2008) and $p W O X 4: Y F P$ (Suer et al., 2011) reporter lines were obtained from the Nottingham Arabidopsis Stock Centre (NASC). Seeds were surface sterilized with $40 \%$ bleach solution followed by four times washing with sterile water and germinated, after three days incubation at $4^{\circ} \mathrm{C}$, on $1 / 2 \mathrm{MS}$ (Murashige and Skoog, 1962) medium containing 1\% sucrose, $0.7 \%$ agar at 
$21^{\circ} \mathrm{C}$ and a 16 hours photoperiod. Two-week-old seedlings were transferred to soil and grown at $21^{\circ} \mathrm{C}, 65 \%$ relative humidity and a 16 hours (long day: LD) photoperiod, and potted plants were photographed with a Nikon D5300 camera.

\section{Plasmid construction}

To generate the $p P X Y$ :AHL15 construct, upstream regions of approximately $3 \mathrm{~kb}$ from the ATG initiation codon of the PXY (AT5G61480) gene was amplified from ecotype Columbia (Col-0) genomic DNA using the forward (F) and reverse (R) PCR primers indicated in Supplementary Table 1. The resulting fragments were first recombined into pDONR207 by a BP reaction and subsequently cloned upstream of the $A H L 15$ cDNA fragment in previously made destination vector $p G W$-AHL15 (Karami et al., 2020a) by a LR reaction according to Gateway cloning procedures (Clonetech). To generate the $p P X Y: I P T$ construct, the AHL15 gene in the $p P X Y: A H L 15$ construct was replaced by a KpnI and XbaI flanked fragment containing the IPT gene from Agrobacterium tumefaciens (Van Der Graaff et al., 2001). All binary vectors were introduced into Agrobacterium tumefaciens strain AGL1 by electroporation (den Dulk-Ras and Hooykaas, 1995). Subsequently, Arabidopsis Col-0, ahl15, and wox4wox14pxy plants were transformed using the floral dip method (Clough and Bent, 1998).

\section{RNA preparation and quantitative real-time PCR (qRT-PCR)}

RNA was isolated from rosette base nodes, and the basal part of inflorescence stems (about $0.5 \mathrm{~cm}$ above rosette base) using the RNEasy(C) kit (Qiagen). First-strand cDNA was synthesized using the RevertAid RT Reverse Transcription kit (Thermo Fischer Scientific). Quantitative PCR was performed on three biological replicates along with three technical replicates using the SYBR-green dye premixed master-mix (Thermo Fischer Scientific) in a C1000 Touch $\subset$ thermal cycler (BIO-RAD). CT values were obtained using Bio-Rad CFX manager 3.1. The relative expression level of genes was calculated according to the $2^{-\Delta \Delta \mathrm{Ct}}$ method (Livak and Schmittgen, 2001), and expression was normalized by using the $\beta$ TUBULIN-6 gene as a reference, analyzed and plotted into graphs in GraphPad Prism 8. The primers used for each gene are described in Supplementary Table 1.

\section{Histology and microscopy}

To analyze stem secondary growth and lignification, the base part (bottom-most) of the main inflorescence stem was cut and sectioned freshly using a razor blade (Wilkinson Sword) (very thin-fresh free-hand cross-sections), which were kept on the ice up to the staining in 3\% phloroglucinol-HCL (0.3 g phloroglucinol, $10 \mathrm{ml}$ absolute ethanol, $5 \mathrm{ml} 37 \% \mathrm{HCL}$ ), using a protocol from Mitra \& Loqué 2014 (Pradhan Mitra and Loqué, 2014). Sections were further analyzed under a light microscope (Nikon eclipse Ci-E/Ci-L). The secondary xylem (SX) width was measured with ImageJ in the way three randomly selected interfascicular parts of the individual stem were measured and divided by 3 to have SX width per stem. For embedded sections, the basal part (bottom-most) of the 1or 2 -month old main inflorescence stem segments at least $1 \mathrm{~cm}$ in length (including the stem base) were harvested and were fixed overnight in $4 \%$ formaldehyde in a $50 \mathrm{mM}$ phosphate solution. The stems were dehydrated 
in a graded ethanol series $(70 \%, 80 \%, 90 \%, 96 \%, 100 \%)$ and embedded in epoxy resin molds. Sections $(3-4 \mu \mathrm{m})$ cut by rotary microtome (Leica RM2265) were stained with $0.01 \%$ aqueous toluidine blue, before being analyzed under a light microscope (Nikon eclipse Ci$\mathrm{E} / \mathrm{Ci}-\mathrm{L})$.

Histochemical $\beta$-glucuronidase (GUS) staining was performed as described previously (Anandalakshmi et al.,1998). The stem segments were cut one centimeter above the basal part and placed in the vial tubes containing cold acetone $90 \%$ on ice, after vacuum infiltration and keeping them on ice the protocol followed with two-time washing and vacuum infiltration afterward transferring to GUS staining solution (containing X-gluc), at the end staining reaction was allowed to proceed around 2 hours at $37^{\circ} \mathrm{C}$ in the dark. After rehydration in a graded ethanol series $(75,50$, and $25 \%)$, the stained tissues were cut freshly by razor blade (very thin-fresh free-hand cross-sections) and observed and photographed using a light microscope (Nikon eclipse $\mathrm{Ci}-\mathrm{E} / \mathrm{Ci}-\mathrm{L}$ ). For quantitative analyses, at least seven plants were analyzed for each data point. Cellular and subcellular localization of GFP and YFP protein in fresh hand section stem on microscopy slide covered with coverslip were visualized using the confocal laser scanning microscope (ZEISS-003-18533) with a 534 laser, $488 \mathrm{~nm}$ LP excitation and 500-525 nm BP emission filters for GFP and YFP signals. All Photo-based measurements performed in Image J then analyzed and plotted into graphs in GraphPad Prism 8.

\section{Transcriptome profiling of stem tissues}

Based on what has been described by Shi et al., 2020, the free-hand cross-sections of the second bottom-most internode of one-month-old Arabidopsis inflorescence stems prepared. Sections belong to different GFP tagged promoter reporter lines (NST3pro:H4-GFP, VND7pro:H4-GFP, PXYpro:H4-GFP, SMXL5pro:H4-GFP, APLpro:H4-GFP, SCRpro:H4GFP, LTP1pro:H4-GFP) corresponding for xylem and interfascicular fiber, xylem vessels, proximal cambium, distal cambium, phloem region, starch sheath and epidermis respectively. GFP positive and negative nucleus confirmed by confocal microscopy, nucleus isolated (15,000 nuclei per sample), and sorted (three replicate for each sample type). After performing RNA isolation, cDNA library prepared for next-generation sequencing. FANSderived datasets present in this story as an expression of a particular gene in transcriptome data stand for normalized gene read counts of the indicated genes among seven different tissues displayed for each replicate individually. *, ** indicates $\mathrm{p}<0.05$ and 0.01 , respectively in likelihood-ratio test (LRT), null hypothesis to be rejected in the LRT is that among the seven different tissues, genes have similar expression. Read counts analyzed and plotted into graphs in GraphPad Prism 8. 


\section{Acknowledgements}

We thank N. Savant and F. van der Klauw, for generating PXY-AHL15 and PXY-IPT constructs respectively, Gerda Lammers and Merijn de Bakker for their help with microscopy. We are grateful to Ward de winter, Jan Vink, Nick Surtel and Mariel Lavrijsen for their supports.

\section{Author contributions}

A.R. designed and performed the majority of Arabidopsis experiments, with contributions from A.L. A.L analyzed the PXY-AHL15 stem. O.K. and R.O supervised the project. D.S and T.G generated the transcriptome profiling of stem tissues. A.R., O.K. and R.O. wrote the manuscript. 
bioRxiv preprint doi: https://doi.org/10.1101/2020.06.19.162297; this version posted June 20, 2020. The copyright holder for this preprint (which was not certified by peer review) is the author/funder. All rights reserved. No reuse allowed without permission.

\section{References}

Altamura, M.M., Possenti, M., Matteucci, A., Baima, S., Ruberti, I., and Morelli, G. (2001). Development of the vascular system in the inflorescence stem of Arabidopsis. New Phytol. 151: 381-389.

Anandalakshmi, R., Pruss, G. J., Ge, X., Marathe, R., Mallory, A. C., Smith, T. H., and Vance, V.B. (1998). A viral suppressor of gene silencing in plants. Proc. Natl. Acad. Sci. 95: 13079--13084.

Baucher, M., El Jaziri, M., and Vandeputte, O. (2007). From primary to secondary growth: Origin and development of the vascular system. J. Exp. Bot. 58: 3485-3501.

Bhalerao, R.P., Fischer, U., and Turner, S. (2016). Environmental and hormonal control of cambial stem cell dynamics. J. Exp. Bot. 68: 79-87.

Brackmann, K. et al. (2018). Spatial specificity of auxin responses coordinates wood formation. Nat. Commun. 9: 875

Bruno, M. and Jen, S. (2008). Cytokinin and auxin interplay in root stem-cell specification during early embryogenesis. Nature 4: 1094-1097.

Campbell, L., Turner, S., and Etchells, P. (2016). Regulation of vascular cell division. J. Exp. Bot. 68: 27-43.

Chiang, M.H. and Greb, T. (2019). How to organize bidirectional tissue production? Curr. Opin. Plant Biol. 51: $15-21$

Clough, S.J. and Bent, F. (1998). Floral dip: a simplified method for Agrobacterium-mediated transformation of Arabidopsis thaliana. Plant J. 16: 735-743.

Denis, E., Kbiri, N., Mary, V., Claisse, G., Conde e Silva, N., Kreis, M., and Deveaux, Y. (2017). WOX14 promotes bioactive gibberellin synthesis and vascular cell differentiation in Arabidopsis. Plant J. 90: 560572 .

Dewitte, W., Scofield, S., Alcasabas, A.A., Maughan, S.C., Menges, M., Braun, N., Collins, C., Nieuwland, J., Prinsen, E., Sundaresan, V., and Murray, J.A.H. (2007). Arabidopsis CYCD3 D-type cyclins link cell proliferation and endocycles and are rate-limiting for cytokinin responses. Proc. Natl. Acad. Sci. U. S. A. 104: 14537-14542.

Duclercq, J., Petra, J., Simon, S., Montagu, M.C.E. Van, and Benkova, E. Růžička-2009-Cytokinin regulates.pdf.

den Dulk-Ras, A. and Hooykaas, P.J. (1995). Electroporation of Agrobacterium tumefaciens. Methods Mol. Biol. 55: 63-72.

El-Showk, S., Ruonala, R., and Helariutta, Y. (2013). Crossing paths: Cytokinin signalling and crosstalk. Dev. 140: 1373-1383.

Elo, A., Immanen, J., Nieminen, K., and Helariutta, Y. (2009). Stem cell function during plant vascular development. Semin. Cell Dev. Biol. 20: 1097-1106.

Etchells, J.P., Mishra, L.S., Kumar, M., Campbell, L., and Turner, S.R. (2015). Wood formation in trees is increased by manipulating PXY-regulated cell division. Curr. Biol. 25: 1050-1055.

Etchells, J.P., Provost, C.M., Mishr, L., and Turner, S.R. (2013). WOX4 and WOX14 act downstream of the PXY receptor kinase to regulate plant vascular proliferation independently of any role in vascular organisation. Dev. 140: 2224-2234.

Etchells, J.P. and Turner, S.R. (2010). The PXY-CLE41 receptor ligand pair defines a multifunctional pathway that controls the rate and orientation of vascularcell division. Development 137: 767-774.

Fischer, U., Kucukoglu, M., Helariutta, Y., and Bhalerao, R.P. (2019). The dynamics of cambial stem cell activity. Annu. Rev. Plant Biol. 70: 293-319.

Fisher, K. and Turner, S. (2007). PXY, a Receptor-like Kinase Essential for Maintaining Polarity during Plant Vascular-Tissue Development. Curr. Biol. 17: 1061-1066.

Fujimoto, S., Matsunaga, S., Yonemura, M., Uchiyama, S., Azuma, T., and Fukui, K. (2004). Identification of a novel plant MAR DNA binding protein localized on chromosomal surfaces. Plant Mol. Biol. 56: 225239.

Gerttula, S., Zinkgraf, M., Muday, G.K., Lewis, D.R., Ibatullin, F.M., Brumer, H., Hart, F., Mansfield, S.D., Filkov, V., and Groover, A. (2015). Transcriptional and hormonal regulation of gravitropism of woody stems in populus. Plant Cell 27: 2800-2813.

Van Der Graaff, E.E., Auer, C.A., and Hooykaas, P.J.J. (2001). Altered development of Arabidopsis thaliana carrying the Agrobacterium tumefaciens ipt gene is partially due to ethylene effects. Plant Growth Regul. 34: 305-315.

Hirakawa, Y., Kondo, Y., and Fukuda, H. (2010). TDIF peptide signaling regulates vascular stem cell proliferation via the WOX4 homeobox gene in Arabidopsis. Plant Cell 22: 2618-2629.

Immanen, J. et al. (2016). Cytokinin and auxin display distinct but interconnected distribution and signaling profiles to stimulate cambial activity. Curr. Biol. 26: 1990-1997. 
bioRxiv preprint doi: https://doi.org/10.1101/2020.06.19.162297; this version posted June 20, 2020. The copyright holder for this preprint (which was not certified by peer review) is the author/funder. All rights reserved. No reuse allowed without permission.

Jouannet, V., Brackmann, K., and Greb, T. (2015). (Pro)cambium formation and proliferation: Two sides of the same coin? Curr. Opin. Plant Biol. 23: 54-60.

Karami, O., Rahimi, A., Khan, M., Bemer, M., Hazarika, R.R., Mak, P., Compier, M., van Noort, V., and Offringa, R. (2020a). A suppressor of axillary meristem maturation promotes longevity in flowering plants. Nat. Plants 6: 368-376.

Karami, O., Rahimi, A., Mak, P., Horstman, A., Boutilier, K., Compier, M., Van der Zaal, B., and Offringa, R. (2020b). An Arabidopsis AT-hook motif nuclear protein mediates somatic-to-embryonic cell fate conversion coinciding with genome duplication. bioRxiv. Nature com: https://www.biorxiv.org/content/10.1101/2020.01.03.

Livak, K.J. and Schmittgen, T.D. (2001). Analysis of relative gene expression data using real-time quantitative PCR and the 2(-Delta Delta C(T)) Method. Methods 25: 402-408.

Matsumoto-Kitano, M., Kusumoto, T., Tarkowski, P., Kinoshita-Tsujimura, K., Václavíková, K., Miyawaki, K., and Kakimoto, T. (2008). Cytokinins are central regulators of cambial activity. Proc. Natl. Acad. Sci. U. S. A. 105: 20027-20031.

Matsushita, A., Furumoto, T., Ishida, S., and Takahashi, Y. (2007). AGF1, an AT-hook protein, is necessary for the negative feedback of AtGA3ox1 encoding GA 3-oxidase. Plant Physiol. 143: 1152-1162.

Melzer, S., Lens, F., Gennen, J., Vanneste, S., Rohde, A., and Beeckman, T. (2008). Flowering-time genes modulate meristem determinacy and growth form in Arabidopsis thaliana. Nat. Genet. 40: 1489-1492.

Miyashima, S., Sebastian, J., Lee, J.Y., and Helariutta, Y. (2013). Stem cell function during plant vascular development. EMBO J. 32: 178-193.

Miyawaki, K., Tarkowski, P., Matsumoto-Kitano, M., Kato, T., Sato, S., Tarkowska, D., Tabata, S., Sandberg, G., and Kakimoto, T. (2006). Roles of Arabidopsis ATP/ADP isopentenyltransferases and tRNA isopentenyltransferases in cytokinin biosynthesis. Proc. Natl. Acad. Sci. U. S. A. 103: 1659816603.

Ng, K.-H., Yu, H., and Ito, T. (2009). AGAMOUS controls GIANT KILLER, a multifunctional chromatin modifier in reproductive organ patterning and differentiation. PLoS Biol. 7: e1000251.

Nieminen, K., Blomster, T., Helariutta, Y., and Mähönen, A.P. (2015). Vascular cambium development. Arab. B. 13: e0177.

Oh, S., Park, S., and Han, K.H. (2003). Transcriptional regulation of secondary growth in Arabidopsis thaliana. J. Exp. Bot. 54: 2709-2722.

Oles, V., Panchenko, A., and Smertenko, A. (2017). Modeling hormonal control of cambium proliferation. PLoS One 12: 1-21.

Poulios, S. and Vlachonasios, K.E. (2018). Synergistic action of GCN5 and CLAVATA1 in the regulation of gynoecium development in Arabidopsis thaliana. New Phytol. 220: 593-608.

Pradhan Mitra, P. and Loqué, D. (2014). Histochemical staining of Arabidopsis thaliana secondary cell wall elements. J. Vis. Exp.: e51381.

Ragni, L. and Greb, T. (2018). Secondary growth as a determinant of plant shape and form. Semin. Cell Dev. Biol. 79: 58-67.

Randall, R.S. et al. (2015). AINTEGUMENTA and the D-type cyclin CYCD3; 1 regulate root secondary growth and respond to cytokinins. Biol. Open 4: 1229-1236.

Robson, P.R.H., Donnison, I.S., Wang, K., Frame, B., Pegg, S.E., Thomas, A., and Thomas, H. (2004). Leaf senescence is delayed in maize expressing the Agrobacterium IPT gene under the control of a novel maize senescence-enhanced promoter. Plant Biotechnol. J. 2: 101-112.

Rybel, B.D., Mähönen, A.P., Helariutta, Y., and Weijers, D. (2015). Plant vascular development : from early specification to differentiation. Nat. Rev. Mol. Cell Biol. 17: 30-40.

Shi, D., Jouannet, V., Agustí, J., Kaul, V., Levitsky, V., Sanchez, P., Mironova, V. V, and Greb, T. (2020). Tissue-specific transcriptome profiling of the Arabidopsis thaliana inflorescence stem reveals local cellular signatures. bioRxiv preprint d: https://doi.org/10.1101/2020.02.10.941492.

Shi, D., Lebovka, I., Loṕez-Salmeroń, V., Sanchez, P., and Greb, T. (2019). Bifacial cambium stem cells generate xylem and phloem during radial plant growth. Dev. 146: 1-8.

Šimášková, M. et al. (2015). Cytokinin response factors regulate PIN-FORMED auxin transporters. Nat. Commun. 6.

Street, I.H., Shah, P.K., Smith, A.M., Avery, N., and Neff, M.M. (2008). The AT-hook-containing proteins SOB3/AHL29 and ESC/AHL27 are negative modulators of hypocotyl growth in Arabidopsis. Plant J. 54: $1-14$.

Suer, S., Agusti, J., Sanchez, P., Schwarz, M., and Greb, T. (2011). WOX4 imparts auxin responsiveness to cambium cells in arabidopsis. Plant Cell 23: 3247-3259.

T, M. and F, S. (1962). A revised medium for rapid growth and bio assays with tobacco tissue cultures. Physiol. Plant. 15: 473-497.

Wallner, E.-S., Jouannet, V., and Greb, T. (2019). SUPPRESSOR OF MAX2 1-LIKE 5 promotes secondary phloem formation during radial stem growth. JAN: 14670. 
bioRxiv preprint doi: https://doi.org/10.1101/2020.06.19.162297; this version posted June 20, 2020. The copyright holder for this preprint (which was not certified by peer review) is the author/funder. All rights reserved. No reuse allowed without permission.

Wang, N., Bagdassarian, K.S., Doherty, R.E., Kroon, J.T., Connor, K.A., Wang, X.Y., Wang, W., Jermyn, I.H., Turner, S.R., and Etchells, J.P. (2019). Organ-specific genetic interactions between paralogues of the PXY and ER receptor kinases enforce radial patterning in arabidopsis vascular tissue. Dev. 146: 10.1242.

Xiao, C., Chen, F., Yu, X., Lin, C., and Fu, Y.-F. (2009). Over-expression of an AT-hook gene, AHL22, delays flowering and inhibits the elongation of the hypocotyl in Arabidopsis thaliana. Plant Mol. Biol. 71: 39-50.

Zhao, J., Favero, D.S., Peng, H., and Neff, M.M. (2013). Arabidopsis thaliana AHL family modulates hypocotyl growth redundantly by interacting with each other via the PPC/DUF296 domain. Proc. Natl. Acad. Sci. 110: E4688-E4697.

Zhou, J., Wang, X., Lee, J.-Y., and Lee, J.-Y. (2013). Cell-to-cell movement of two interacting AT-hook factors in Arabidopsis root vascular tissue patterning. Plant Cell 25: 187-201.

Zhou, Y., Liu, X., Engstrom, E.M., Nimchuk, Z.L., Pruneda-Paz, J.L., Tarr, P.T., Yan, A., Kay, S.A., and Meyerowitz, E.M. (2015). Control of plant stem cell function by conserved interacting transcriptional regulators. Nature 517: 377-380.

Zürcher, E., Tavor-Deslex, D., Lituiev, D., Enkerli, K., Tarr, P.T., and Müller, B. (2013). A robust and sensitive synthetic sensor to monitor the transcriptional output of the cytokinin signaling network in planta. Plant Physiol. 161: 1066-1075. 
bioRxiv preprint doi: https://doi.org/10.1101/2020.06.19.162297; this version posted June 20, 2020. The copyright holder for this preprint (which was not certified by peer review) is the author/funder. All rights reserved. No reuse allowed without permission.
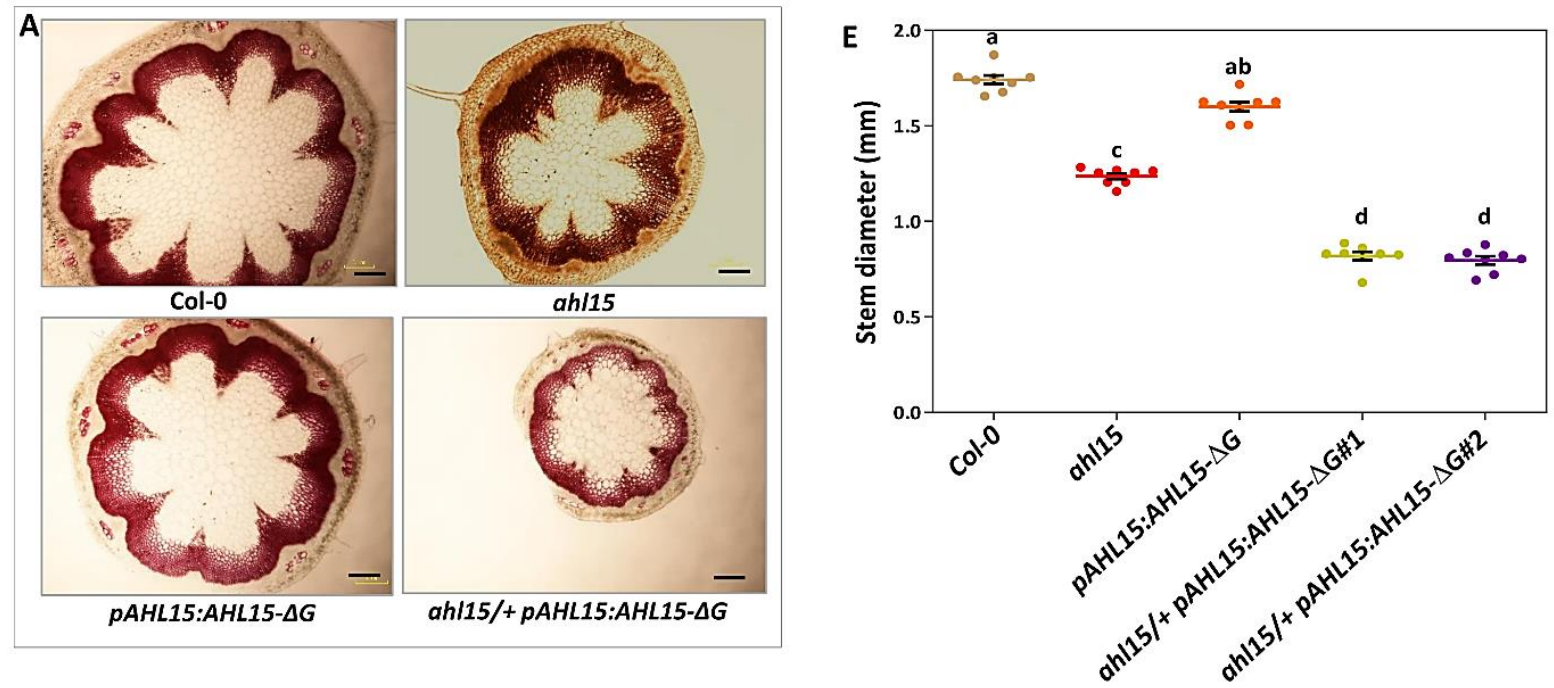

Supplementary Figure 1| $\boldsymbol{A H L}$ genes are essential for secondary growth of Arabidopsis inflorescence stems. (A) Phloroglucinol-stained fresh cross-sections of most-bottom base of one-month-old wild-type (up panel, left), ahl15 (up panel, right), pAHL15:AHL15- $A G$ (down panel, left), and ahl15/+ pAHL15:AHL15- $\triangle G$ (down pane, right) inflorescence stems. (B) Quantification of the stem diameter in one-month-old stem wildtype, ahl15, pAHL15:AHL15- $\triangle G$, and ahl15/+ pAHL15:AHL15- $A G$ plants. Colored dots indicate the number of lateral branches per plant ( $\mathrm{n}=14$ (in $\mathrm{B}$ ) or 10 (in $\mathrm{C}$ ) biologically independent plants), horizontal lines indicate the mean and error bars indicate the s.e.m. Different letters indicate statistically significant differences $(\mathrm{P}<$ 0.01) as determined by a one-way ANOVA with Tukey's honest significant difference post hoc test. Scale bars indicate $0.15 \mathrm{~mm}$. 
bioRxiv preprint doi: https://doi.org/10.1101/2020.06.19.162297; this version posted June 20, 2020. The copyright holder for this preprint (which was not certified by peer review) is the author/funder. All rights reserved. No reuse allowed without permission.

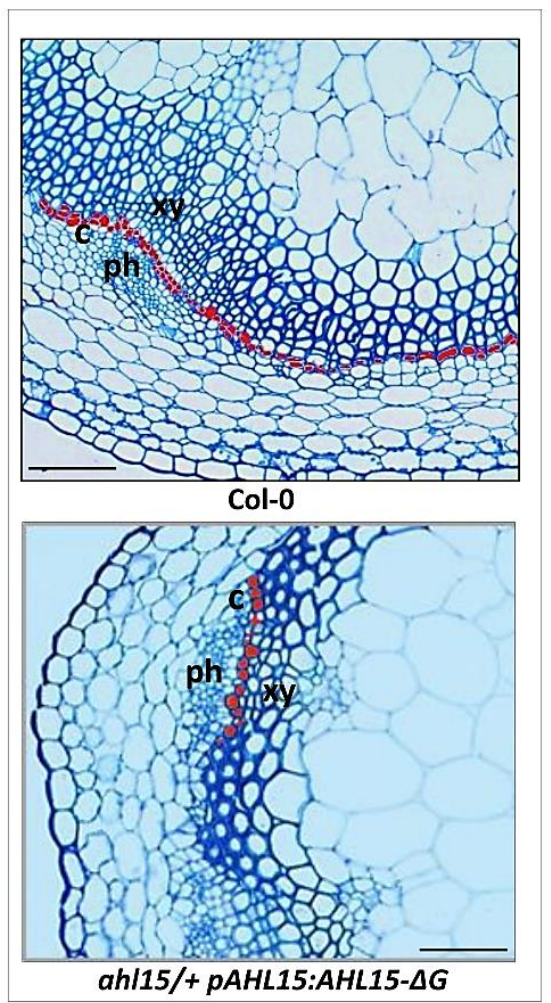

Supplementary Figure 2| ahl15/+pAHL15:AHL15- $\triangle G$ displays normal and organized structure of bundle and interfascicular region compare to wild-type along with delay in cambium initiation. Toluidine bluestained cross-sections of most-bottom base of two-week-old wild-type (upper) and ahl15/+pAHL15:AHL15- $\triangle G$ (lower) inflorescence stems. The red dots mark the cambium/procambial cells in the interfascicular and bundle regions of wild-type and ahl15/+pAHL15:AHL15- $\triangle G$ respectively. Scale bars indicate $0.05 \mathrm{~mm}$. 

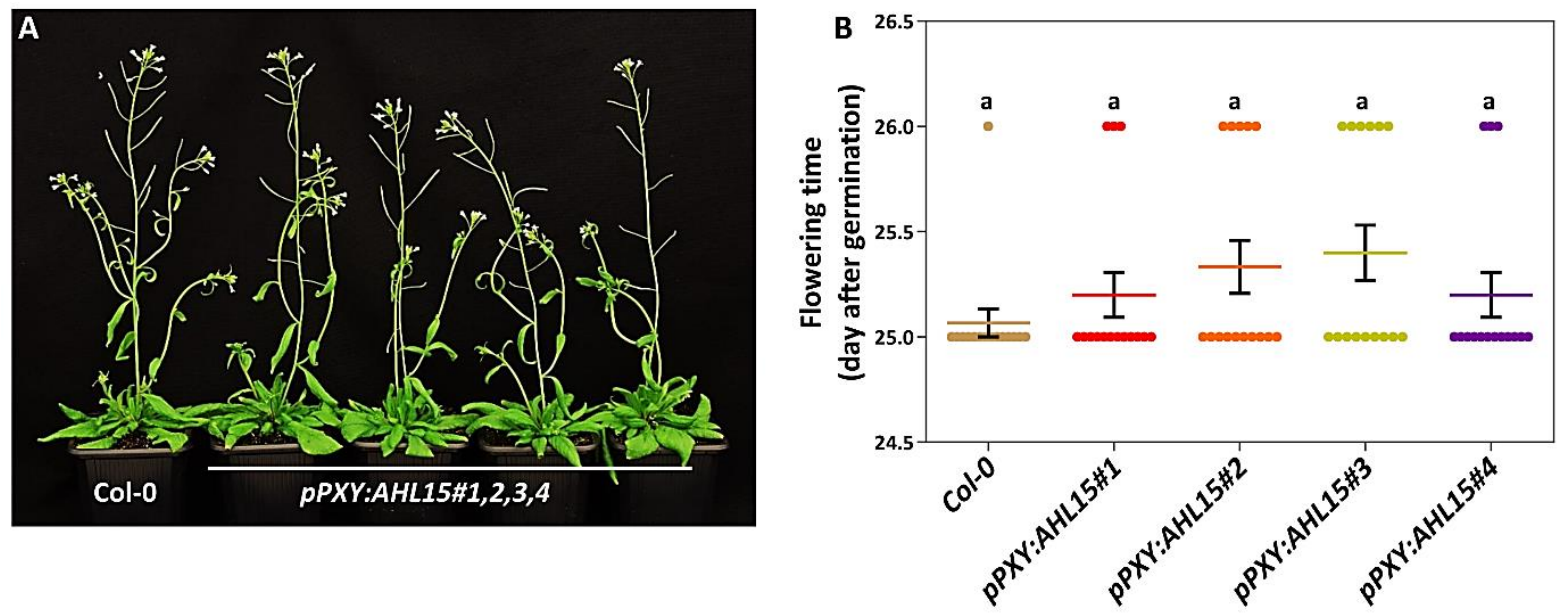

Supplementary Figure 3| Cambium-specific AHL15 overexpression does not affect branching or flowering time in Arabidopsis. (A) The shoot phenotype of 5-week-old wild-type and $p P X Y: A H L 15$ (4 independent lines) plants. (B) Quantification of the flowering time of wild-type and $p P X Y: A H L 15$ plants, as presented in (A). Colored dots indicate the flowering time of individual plants in days after germination $(\mathrm{n}=15$ independent plants per line), horizontal lines indicate the mean and error bars indicate the s.e.m. Different letters indicate statistically significant differences $(\mathrm{P}<0.05)$ as determined by a one-way ANOVA with Tukey's honest significant difference post hoc test.
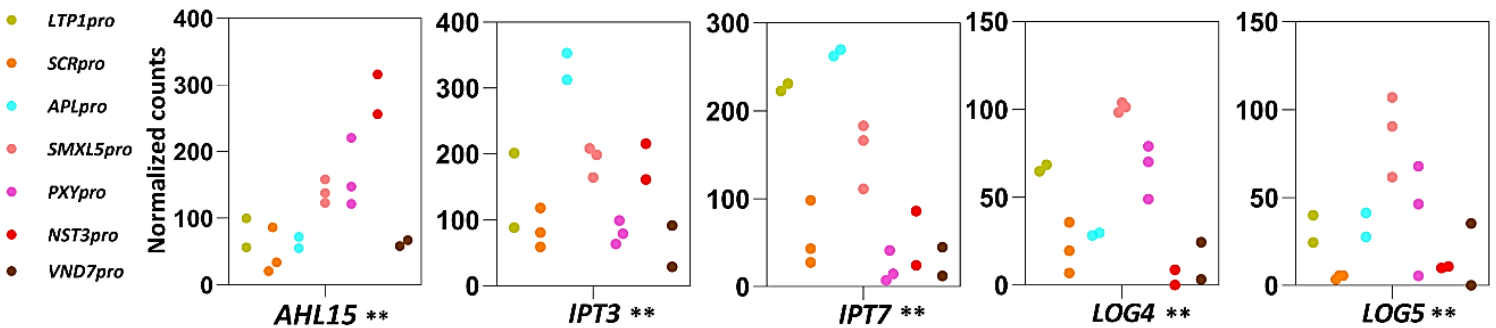

Supplementary Figure $4 \mid A H L 15$ and cytokinin biosynthesis genes are co-expressed in the cambium domain. Co-expression of AHL15 with IPT3, IPT7, LOG4 and LOG5 at cambium and bundle domains. Colored dots indicate the values of two or three biological replicates of RNA isolation obtain by FANS. Normalized gene read counts of the indicated genes among seven different tissues displayed for each replicate individually. *,** indicates $\mathrm{p}<0.05$ and 0.01 , respectively in LRT (Shi et al., 2020). 
bioRxiv preprint doi: https://doi.org/10.1101/2020.06.19.162297; this version posted June 20, 2020. The copyright holder for this preprint (which was not certified by peer review) is the author/funder. All rights reserved. No reuse allowed without permission.

Supplementary Table 1. Primers used for cloning, genotyping and qRT-PCR

\begin{tabular}{lll}
\hline Name* & Sequence (5' to 3') & Purpose \\
\hline PXY-Promoter-F & GGGGACAAGTTTGTACAAAAAAGCAGGCTGCCATACTGTCATCTTGTACCAG & pPXY:AHL15 construct \\
PXY-Promoter-R & GGGGACCACTTTGTACAAGAAAGCTGGGTACGTAGCTTTTAGAAAGAAATTA & pPXY:IPT construct \\
KpnI-IPT-F & AAAGGTACCATGGACCTGCATC & qRT-PCR IPT3 \\
IPT-XbaI-R & AAATCTAGA CTAATACATTCCGAACG & qRT-PCR IPT7 \\
q IPT3-F & GTGGATGCGACTCCAGTCTT & \\
q IPT3-R & CACTAGACACCGCGACAACT & qRT-PCR LOG4 \\
q IPT7-F & GACGCCACTGAGGTGTTCTT & qRT-PCR LOG5 \\
q IPT7-R & TGGGCTCTACTTCCACTTCC & \\
q LOG4-F & GGTTTGCTTTGTAATGATTTCTGGG & \\
q LOG4-R & ACTTCCTTAGATGGGCAAAACACGC & \\
q LOG5-F & TCAAACCATCTCAGCGTCAC & \\
q LOG5-R & AGGGCAATCTCAGTCTGCAT & \\
& & \\
\hline
\end{tabular}

*, F: forward; R: reverse. 